Supporting Information

\title{
Bioinspired Mechanically Responsive Hydrogel upon Redox Mediated by Dynamic Coordination between Telluroether and Platinum Ions
}

Feng $\mathrm{Li}^{\mathrm{a} \ddagger}$, Xue Zhang ${ }^{\mathrm{a} \ddagger}$, Shuxian $\mathrm{Hu}^{\mathrm{b} \ddagger}$, Zhaoyue $\mathrm{Lv}^{\mathrm{a}}$, Jigang $\mathrm{Lv}^{\mathrm{a}}$, Wenting $\mathrm{Yu}^{\mathrm{a}}$, Xihan Xu $\mathrm{X}^{\mathrm{a}}$, Dayong Yang $^{\text {a* }}$

${ }^{\text {a } F r o n t i e r ~ S c i e n c e ~ C e n t e r ~ f o r ~ S y n t h e t i c ~ B i o l o g y, ~ K e y ~ L a b o r a t o r y ~ o f ~ S y s t e m s ~ B i o e n g i n e e r i n g ~(M O E), ~}$ School of Chemical Engineering and Technology, Tianjin University, Tianjin 300350, P.R. China.

${ }^{\mathrm{b}}$ Beijing Computational Science Research Center, Beijing 100193, P.R. China.

*Corresponding author: dayong.yang@tju.edu.cn

${ }^{\ddagger}$ Feng Li, Xue Zhang, and Shuxian Hu contributed equally to this work. 


\section{Experimental Section}

\section{Materials}

Tellurium powder, 3-Bromopropylamine, 2-Methyl-2-propenoyl chloride, N-hydroxyethyl acrylamide (HEMAA) and TEMED were purchased from Energy Chemical Co. Ltd. Hydrogen peroxide $\left(\mathrm{H}_{2} \mathrm{O}_{2}\right)$ was obtained from Aladdin Chemical Co. Ltd. Sodium borohydride was obtained from TianJin FuChen Chemical Co. Ltd. Platinum(IV) chloride was purchased by J \& K Chemical Technology Co. Ltd. L-ascorblcacid (VC) was purchased from Beijing Dingguochangsheng Biotechnology Co. Ltd. Ammonium persulfate was obtained from Solarbio Chemical Co. Ltd. All chemicals were the analytical reagent quality and used as received unless otherwise stated.

\section{Methods}

\section{Synthesis of 3,3'-tellurobis(propan-1-amine)}

Tellurium containing molecule 3,3'-tellurobis(propan-1-amine) was synthesized through the reaction of disodium telluride and 3-bromopropylamine. Disodium telluride was prepared through reaction between Te powder and excess amount of sodium borohydride. Initially, $0.848 \mathrm{~g}(22 \mathrm{mmol})$ sodium borohydride was dissolved in $20 \mathrm{~mL}$ water in a round-bottom flask at $50{ }^{\circ} \mathrm{C}$ with magnetic stirring in an atmosphere of $\mathrm{N}_{2}$. Then, $1.02 \mathrm{~g}(8 \mathrm{mmol})$ tellurium power was added into the above solution. When the solution became colorless, $3.502 \mathrm{~g}$ (16mmol) 3-Bromopropylamine hydrobromide dissolved in $20 \mathrm{~mL}$ tetrahydrofuran (THF) was added into the above solution with stirring to react for $24 \mathrm{~h}$. Then THF was removed and the residue was extracted by dichloromethane (DCM) and washed three times by sodium hydroxide solution. Finally, the DCM was desiccated with anhydrous magnesium sulfate. A yellow liquid was obtained after vacuum drying. Yield: $45 \%$. Synthesis of N,N'-(tellurobis(propane-3,1-diyl))bis(2-methylacrylamide) (donated as Acry2Te)

Acry2-Te was synthesized through the reaction of 2-Methyl-2-propenoyl chloride and 3,3'tellurobis(propan-1-amine). In detail, 3-Bromopropylamine was dissolved in $20 \mathrm{~mL}$ of THF and degassed by $\mathrm{N}_{2}$ for $20 \mathrm{~min}$ in a round-bottom flask with stirring. Then, $0.752 \mathrm{~g}$ (7.2 mmol) 2-Methyl2-propenoyl chloride dissolved in $20 \mathrm{~mL}$ THF was injected into the flask and kept stirring for $48 \mathrm{~h}$. Products were concentrated, extracted by DCM, washed by sodium chloride solution, and desiccated 
by anhydrous magnesium sulfate successively. Yellow viscous liquid was generated after vacuum drying with a yield of $50 \%$.

\section{Nuclear paramagnetic resonance spectroscopy}

Nuclear magnetic resonance (NMR) spectroscopy spectra were performed on an AVANCE IIITM HD $400 \mathrm{MHz}$ NanoBAY (Brook, China) nuclear magnetic resonance spectrometer. The solvent of NMR tests was DMSO-d6.

\section{Surface photoelectron spectroscopy}

X-ray photoelectron spectra of all the samples were recorded on Thermo Scientific ESCALAB 250Xi (Thermo, USA) X-ray surface photoelectron spectroscopy (XPS) instrument.

\section{Preparation of Hydrogel}

For the preparation of hydrogel, firstly, $40 \% \mathrm{~N}$-hydroxyethyl acrylamide (HEMAA) was added into water. Then, Acry2-Te solution was added into the above solution. 10\% APS and TEMED were added into the reaction successively under an atmosphere of nitrogen. After 10 minutes, it became a transparent hydrogel. $\mathrm{PtCl}_{4}$ aqueous solution was added into the hydrogel for $12 \mathrm{~h}$. The hydrogel became yellow. Then, $\mathrm{H}_{2} \mathrm{O}_{2}$ aqueous solution was added into the hydrogel for $12 \mathrm{~h}$. VC aqueous solution was added into the hydrogel for $12 \mathrm{~h}$. The prescription for hydrogel has been included in Table 2.

\section{Computational details}

Gas phase geometry optimizations were performed with the generalized gradient approximation (GGA) with the PBE functional as implemented in the Gaussian 09 package. The scalar-relativistic Stuttgart energy-consistent pseudopotential with 18-valence-electrons and the associated ECP60MWB valence basis set were used for Pt, with 6-valence-electrons and the associated ECP46MWB_VTZ valence basis set were used for Te, and Dunning's correlation consistent allelectron basis sets with polarized triple-zeta (cc-pVTZ) were used for $\mathrm{O}, \mathrm{C}$ and $\mathrm{H}^{1-3}$ This methodology has been successfully applied to other platinum-containing systems. Geometry optimizations were performed without symmetry restrictions and were followed by vibrational frequency analysis to assign optimized structures as local minima or saddle points. Reaction energies were obtained by combining the electronic energies with zero-point vibrational energy corrections. Then, the Polarizable Continuum solvation model (PCM) via placing the solute in a cavity within the solvent reaction field was employed to model the presence of water solvent and to 
consider the approximate effects of water on the electronic and geometric structures of the complexes. ${ }^{4}$ The DFT calculations were performed with the broken symmetry option (unrestricted calculations). All stationary points were confirmed as minima by vibrational analysis. The initial starting points for geometry optimizations were truncated from the experimental ligand structures of Acry2-Te where the $-\mathrm{CH}_{2}-\mathrm{NH}-\mathrm{CO}-\mathrm{CH}\left(\mathrm{CH}_{3}\right)=\mathrm{CH}_{2}$ groups were replaced with ethyl, denoted as $\mathrm{CH}_{3} \mathrm{CH}_{2}-\mathrm{Te}-\mathrm{CH}_{2} \mathrm{CH}_{3}$.

\section{Rheological Test}

The mechanical properties of hydrogel were characterized with AR-G2 rheometer (TA Instruments, USA). Time-sweep oscillatory tests were performed with a $20 \mathrm{~mm}$ parallel-plate geometry, using $200 \mu \mathrm{L}$ of hydrogels, at a fixed strain of $1 \%$ and a fixed frequency $(1 \mathrm{~Hz})$ at $25{ }^{\circ} \mathrm{C}$ for $3 \mathrm{~min}$. The data presented in the paper were collected in the last 15 seconds of steady states.

\section{SEM Characterization}

For the micromorphology characterization, the hydrogel was imaged with a field mission scanning electron microscope (SEM, Hitachi S-4800, Japan). For sample preparation, the prepared colloids were frozen by immersing them in liquid nitrogen; then, a thin layer was cut off with a knife, placed on a silicon wafer, and freeze-dried in a vacuum freeze-dryer for $12 \mathrm{~h}$. The resulting samples were further coated with Au for the following imaging.

\section{Mass Spectrometry}

For the sample preparation, $0.01898 \mathrm{~g}$ of Acry2-Te and $0.00842 \mathrm{~g}$ of $\mathrm{PtCl}_{4}$ were dissolved in $1 \mathrm{~mL}$ of dimethyl sulfoxide under an atmosphere of nitrogen. After $24 \mathrm{~h}$, the solution was filtered with a pore size of $0.22 \mu \mathrm{m}$. The mass spectrometry was collected by liquid chromatography-high resolution tandem mass spectrometer (Autoflex tof/tofIII, Bruker, USA). 
Figures and tables

A) ${ }_{\mathrm{H}_{2} \mathrm{~N}} \mathrm{Br}_{\mathrm{Na}}+\mathrm{Na}_{2} \mathrm{Te} \underset{\mathrm{H}_{2} \mathrm{O} / \mathrm{THF}}{5^{\circ} \mathrm{C} / \mathrm{N}_{2}} \stackrel{4}{\mathrm{H}_{2} \mathrm{~N}} \overbrace{2}^{3}$

B)

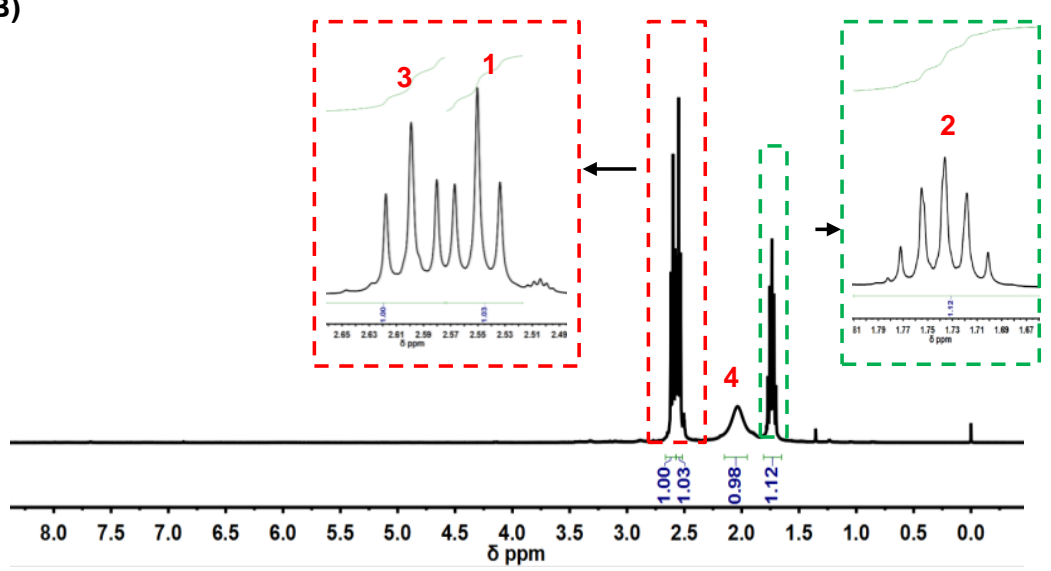

Figure S1. The synthetic routes and ${ }^{1} \mathrm{H}$ NMR spectra of 3,3'-tellurobis(propan-1-amine) (400 MHz, DMSO-D6, 298 K). A) The synthetic routes of Arcy-Te. B) ${ }^{1} \mathrm{H}$ NMR spectra of the synthesized 3,3'-tellurobis(propan-1-amine) $\delta(\mathrm{ppm}): 2.6\left(4 \mathrm{H}, \mathrm{t}, \mathrm{TeCH}_{2} \mathrm{CH}_{2} \mathrm{CH}_{2}\right), 1.74\left(4 \mathrm{H}, \mathrm{m}, \mathrm{TeCH}_{2} \mathrm{CH}_{2} \mathrm{CH}_{2}\right.$ ), 2.55 (4H, t, $\left.\mathrm{TeCH}_{2}\right), 2.05\left(4 \mathrm{H}, \mathrm{t}, \mathrm{TeCH}_{2} \mathrm{CH}_{2} \mathrm{CH}_{2} \mathrm{NH}_{2}\right)$. 
A)

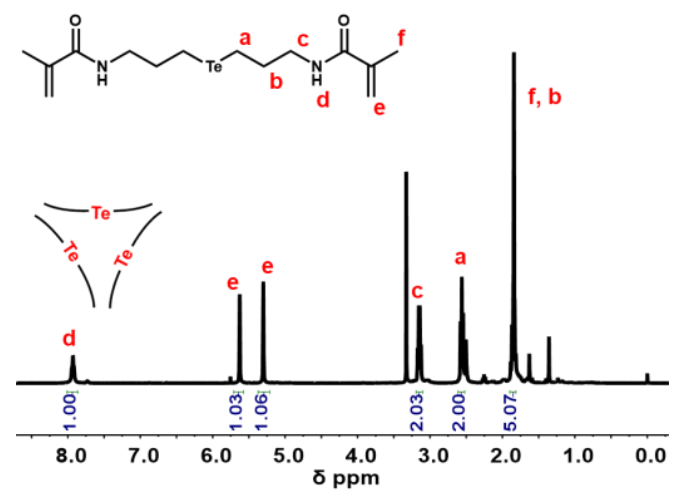

C)

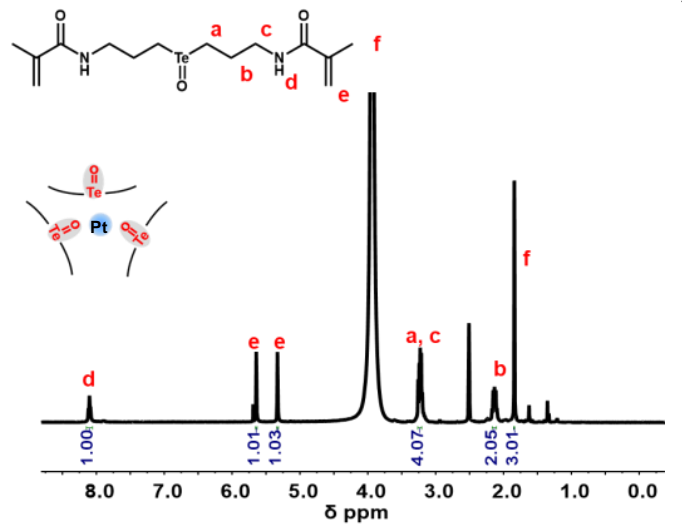

B)

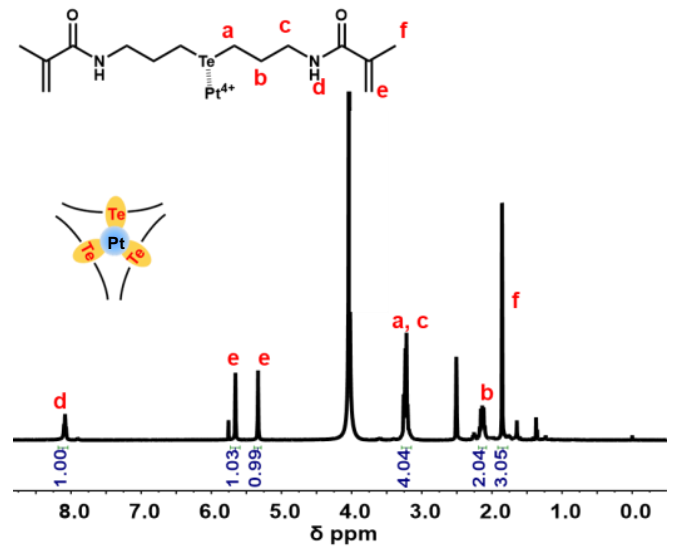

D)

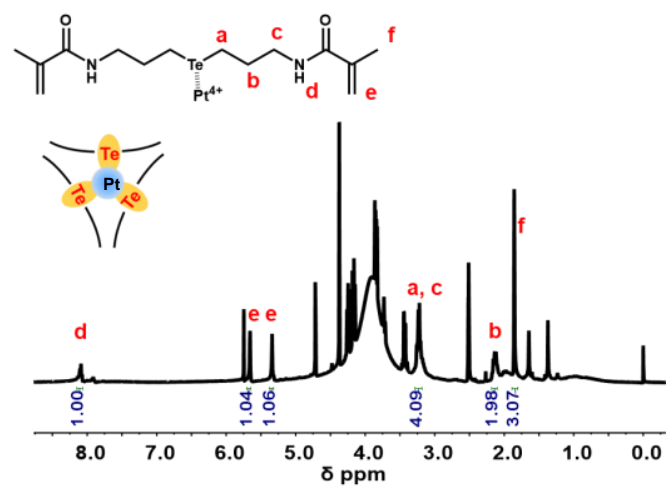

Figure S2. A) ${ }^{1} \mathrm{H}$ NMR spectra of the synthesized Arcy2-Te $\delta(\mathrm{ppm}): 2.56(\alpha, 4 \mathrm{H}, \mathrm{t}$, $\left.\mathrm{TeCH} \mathrm{CH}_{2}\right), 1.84\left(1 \mathrm{HH}, \mathrm{m}, \mathrm{TeCH}_{2} \mathrm{CH}_{2}\right.$ and $\left.\mathrm{CCH}_{3}\right), 3.15\left(4 \mathrm{H}, \mathrm{q}, \mathrm{TeCH}_{2} \mathrm{CH}_{2} \mathrm{CH}_{2}\right), 5.31(2 \mathrm{H}$, s, $\left.\left.\mathrm{C}=\mathrm{CH}_{2}\right), 5.63\left(2 \mathrm{H}, \mathrm{s}, \mathrm{C}=\mathrm{CH}_{2}\right), 7.93\left(2 \mathrm{H}, \mathrm{t}, \mathrm{TeCH}_{2} \mathrm{CH}_{2} \mathrm{CH}_{2} \mathrm{NH}\right) . \mathbf{B}\right)$ The ${ }^{1} \mathrm{H} \mathrm{NMR}$ spectra of coordination complex Acry2-Te-Pt $\delta(\mathrm{ppm}): 3.22\left(8 \mathrm{H}, \mathrm{m}, \mathrm{TeCH}_{2}\right.$ and $\left.\mathrm{TeCH}_{2} \mathrm{CH}_{2} \mathrm{CH}_{2}\right), 1.86(6 \mathrm{H}, \mathrm{s}, \mathrm{CCH}), 2.14\left(4 \mathrm{H}, \mathrm{m}, \mathrm{TeCH}_{2} \mathrm{CH}_{2}\right), 5.33\left(2 \mathrm{H}, \mathrm{s}, \mathrm{C}=\mathrm{CH}_{2}\right)$, $\left.5.66\left(2 \mathrm{H}, \mathrm{s}, \mathrm{C}=\mathrm{CH}_{2}\right), 8.06\left(2 \mathrm{H}, \mathrm{t}, \mathrm{TeCH}_{2} \mathrm{CH}_{2} \mathrm{CH}_{2} \mathrm{NH}\right) . \mathrm{C}\right)$ The ${ }^{1} \mathrm{H}$ NMR spectra of Acry2-TeO $\delta$ (ppm): $3.22\left(8 \mathrm{H}, \mathrm{m}, \mathrm{TeCH}_{2}\right.$ and $\left.\mathrm{TeCH}_{2} \mathrm{CH}_{2} \mathrm{CH}_{2}\right), 1.86\left(6 \mathrm{H}, \mathrm{s}, \mathrm{CCH}_{3}\right)$, $2.13\left(4 \mathrm{H}, \mathrm{m}, \mathrm{TeCH}_{2} \mathrm{CH}_{2}\right), 5.33\left(2 \mathrm{H}, \mathrm{s}, \mathrm{C}=\mathrm{CH}_{2}\right), 5.64\left(2 \mathrm{H}, \mathrm{s}, \mathrm{C}=\mathrm{CH}_{2}\right), 8.11(2 \mathrm{H}, \mathrm{t}$, $\mathrm{TeCH}_{2} \mathrm{CH}_{2} \mathrm{CH}_{2} \mathrm{NH}$ ). D) The ${ }^{1} \mathrm{H}$ NMR spectra of Acry2-Te-Pt reduced from Acry2-TeO and $\mathrm{Pt}(\mathrm{IV})$ ions mixed system, $\delta$ (ppm): $3.22\left(8 \mathrm{H}, \mathrm{m}, \mathrm{TeCH}_{2}\right.$ and $\left.\mathrm{TeCH}_{2} \mathrm{CH}_{2} \mathrm{CH}_{2}\right), 1.86$ $\left(6 \mathrm{H}, \mathrm{s}, \mathrm{CCH}_{3}\right), 2.13\left(4 \mathrm{H}, \mathrm{m}, \mathrm{TeCH}_{2} \mathrm{CH}_{2}\right), 5.33\left(2 \mathrm{H}, \mathrm{s}, \mathrm{C}=\mathrm{CH}_{2}\right), 5.64\left(2 \mathrm{H}, \mathrm{s}, \mathrm{C}=\mathrm{CH}_{2}\right)$, $8.1\left(2 \mathrm{H}, \mathrm{t}, \mathrm{TeCH}_{2} \mathrm{CH}_{2} \mathrm{CH}_{2} \mathrm{NH}\right)$. The solvent of NMR tests was DMSO-d6. 
A)
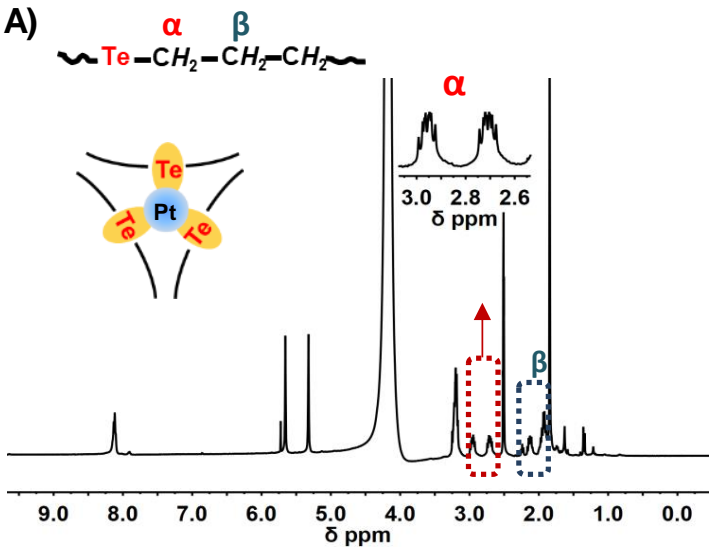

B)

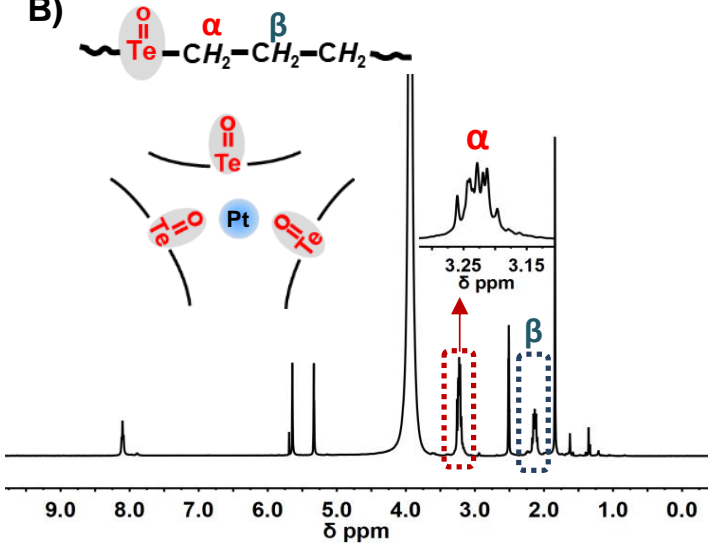

Figure S3. A) ${ }^{1} \mathrm{H}$ NMR spectra of Acry2-Te and Pt (II) coordinated complex $\delta$ ppm: 2.73 and 2.97 (4H, t, $\left.\mathrm{Te} \mathrm{CH}_{2}\right), 1.86(6 \mathrm{H}, \mathrm{s}, \mathrm{CCH}), 1.95\left(4 \mathrm{H}, \mathrm{m}, \mathrm{TeCH}_{2} \mathrm{CH}_{2}\right), 3.2\left(4 \mathrm{H}, \mathrm{q}, \mathrm{TeCH}_{2} \mathrm{CH}_{2} \mathrm{CH}_{2}\right), 5.33$ $\left.\left(2 \mathrm{H}, \mathrm{m}, \mathrm{C}=\mathrm{CH}_{2}\right), 5.66\left(2 \mathrm{H}, \mathrm{m}, \mathrm{C}=\mathrm{CH}_{2}\right), 8.06\left(2 \mathrm{H}, \mathrm{t}, \mathrm{TeCH}_{2} \mathrm{CH}_{2} \mathrm{CH}_{2} \mathrm{NH}\right) . \mathbf{B}\right){ }^{1} \mathrm{H}$ NMR spectra of oxidation of Acry2-Te-Pt(II) complex system: 2.73 and $2.97\left(4 \mathrm{H}, \mathrm{t}, \mathrm{Te} \mathrm{CH}_{2}\right), 1.86\left(6 \mathrm{H}, \mathrm{s}, \mathrm{CCH}_{3}\right)$, $1.95\left(4 \mathrm{H}, \mathrm{m}, \mathrm{TeCH}_{2} \mathrm{CH}_{2}\right), 3.2\left(4 \mathrm{H}, \mathrm{q}, \mathrm{TeCH}_{2} \mathrm{CH}_{2} \mathrm{CH}_{2}\right), 5.33\left(2 \mathrm{H}, \mathrm{m}, \mathrm{C}=\mathrm{CH}_{2}\right), 5.66\left(2 \mathrm{H}, \mathrm{m}, \mathrm{C}=\mathrm{CH}_{2}\right)$, $8.06\left(2 \mathrm{H}, \mathrm{t}, \mathrm{TeCH}_{2} \mathrm{CH}_{2} \mathrm{CH}_{2} \mathrm{NH}\right)$. 
A)

1 Acry2-Te

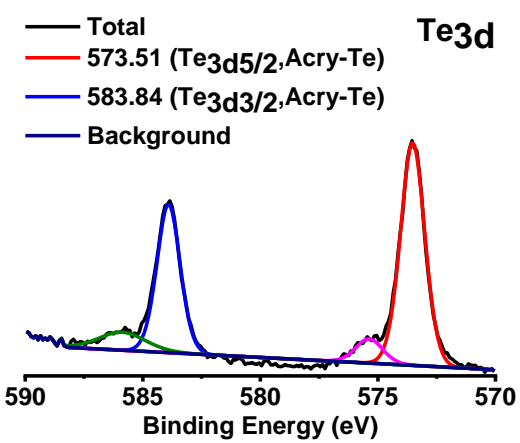

C)

3 Acry2-TeO (Acry2-Te- $\mathrm{Pt}+\mathrm{H}_{2} \mathrm{O}_{2}$ )

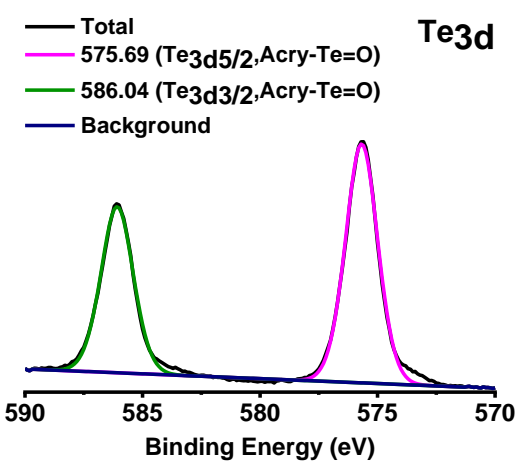

B) 2 Acry2-Te-Pt

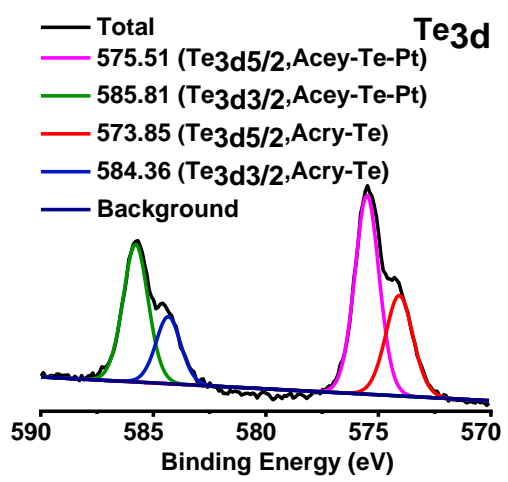

D)

4 R-Acry2-Te-Pt (Acry2-Te- $\mathrm{Pt}+\mathrm{H}_{2} \mathrm{O}_{2}+\mathrm{VC}$ )

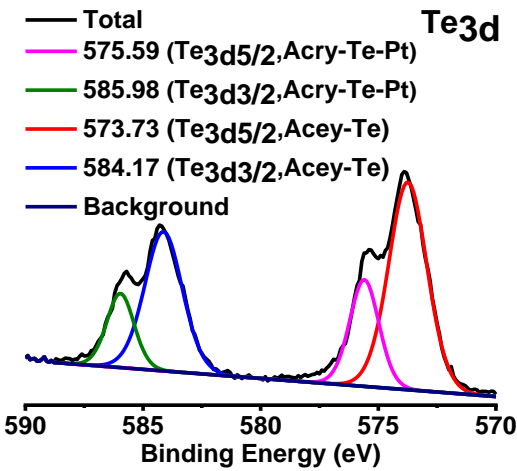

Figure S4. Deconvoluted XPS spectra of Te3d in Acry2-Te (A), Acry2-Te-Pt (B), Acry2-TeO (C), and R-Acry2-Te-Pt (D). 
A) $\mathrm{PtCl}_{4}$

1,3: Pt(IV)

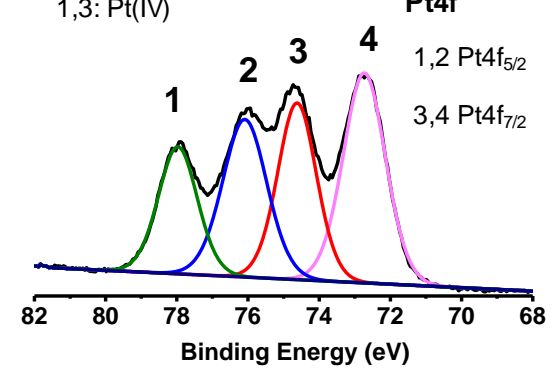

C) Acry2-Te-Pt+ $\mathrm{H}_{2} \mathrm{O}_{2}$

1,3: Pt(IV)

Pt4f

1,2 $\mathrm{Pt} 4 \mathrm{f}_{5 / 2}$

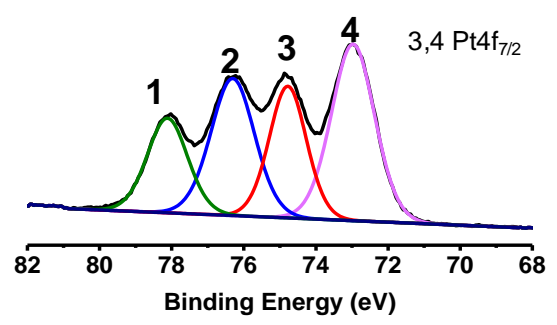

B) Acry2-Te-Pt

1,3: Pt(IV)

Pt4f

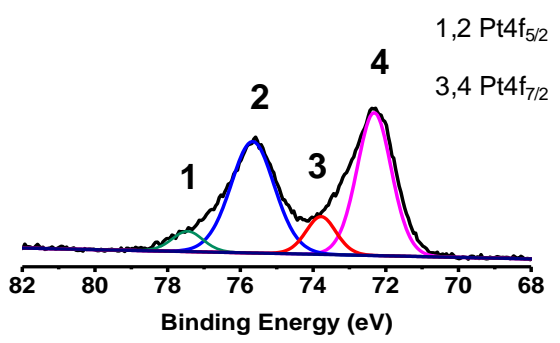

D) Acry2-Te-Pt+ $\mathrm{H}_{2} \mathrm{O}_{2}+\mathrm{VC}$

1,3: $\mathrm{Pt}(\mathrm{IV})$

Pt4f

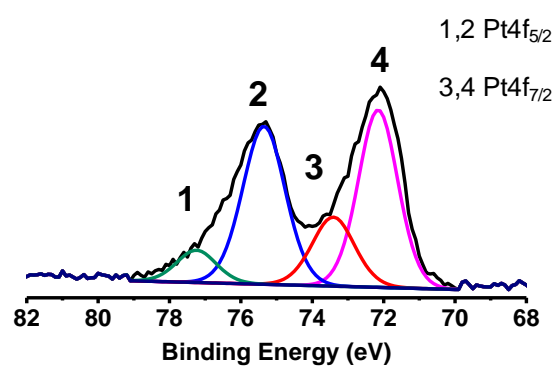

Figure S5. The deconvoluted XPS spectra of Pf4f in $\mathrm{PtCl}_{4}(\mathbf{A})$, Acry2-Te-Pt (B), Acry2-TeO (C), and R-Acry2-Te-Pt (D). 
A)

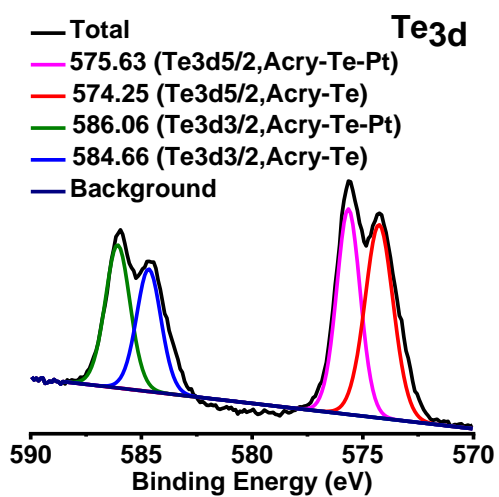

B)

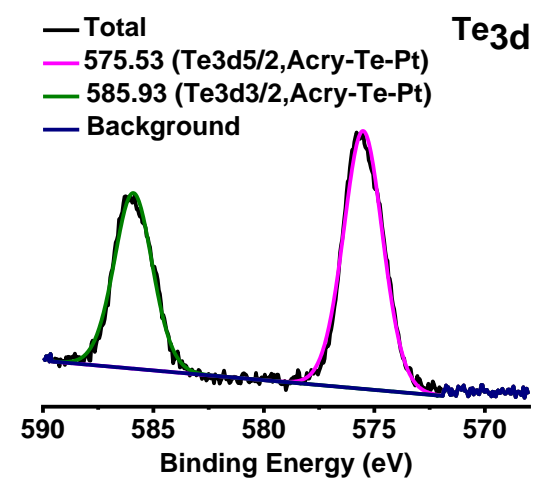

Figure S6. The deconvoluted XPS spectra of Te3d in Arcy2-Te and $\mathrm{PtCl}_{4}$ mixed solution with stoichiometric ratio of $\mathrm{PtCl}_{4}$ and Acry2-Te 1:3 (A) and 1:1 (B). 
A)

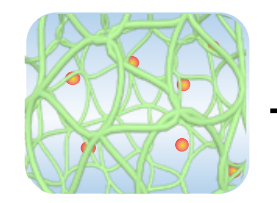

$\sqrt{ }$
B)

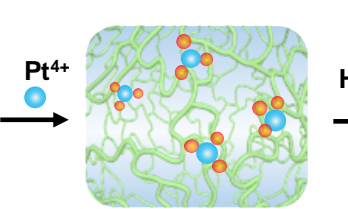

$\sqrt{2}$
C)

D)

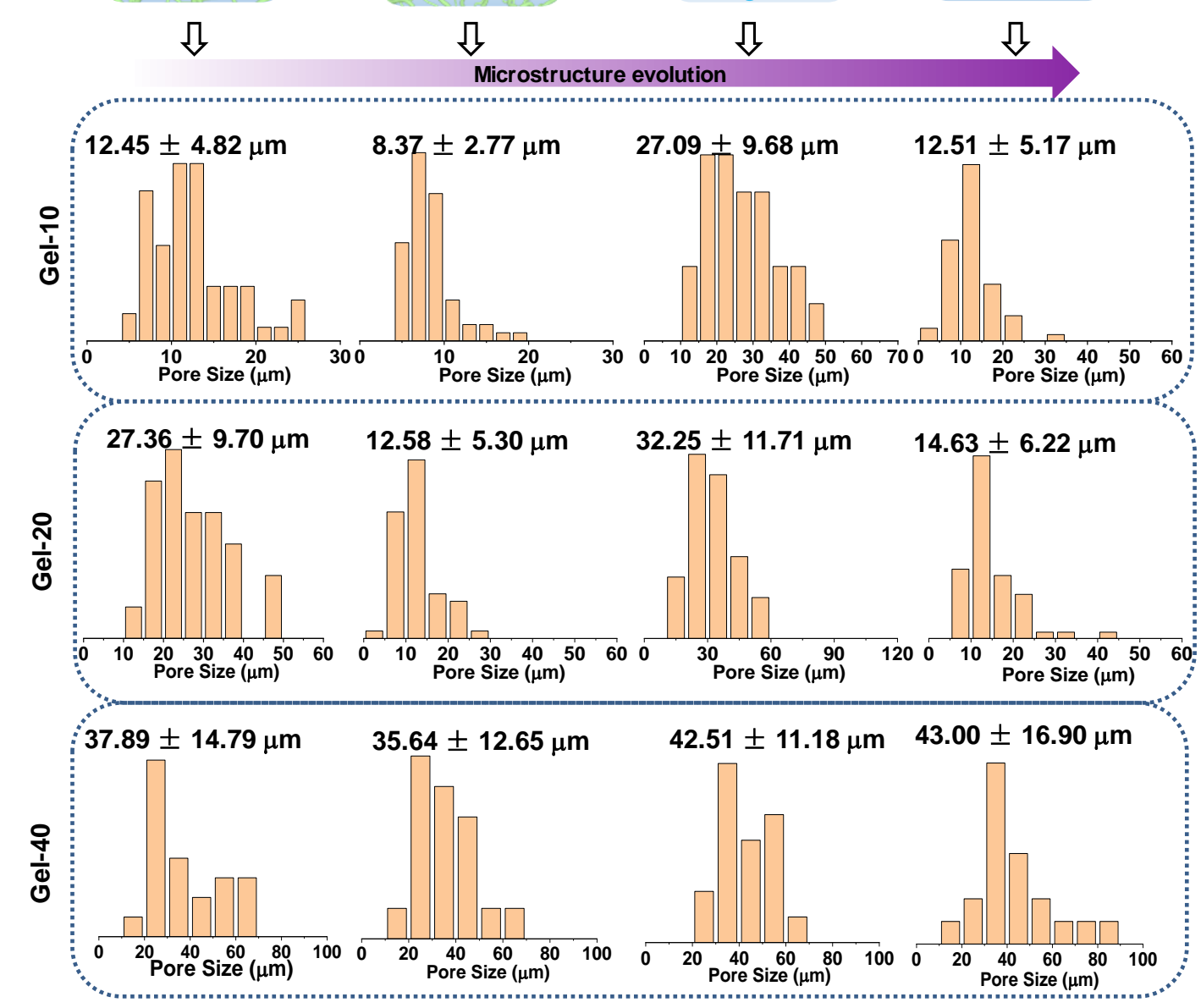

Figure S7. Pore size evolution of dynamic hydrogel analysed using image J software based on the SEM images in Figure 4. A) Pore size of hydrogels fabricated via free radical copolymerization of Acry2-Te with HEMAA. B) Pore size of evolutionary hydrogels by introducing Pt(IV) into hydrogel in (A). C) Pore size of oxidative hydrogel from hydrogel in (B) by using $\mathrm{H}_{2} \mathrm{O}_{2}$ as oxidant. D) Pore size of reduced hydrogel from hydrogel in $(\mathbf{C})$ by using VC as reductant. 

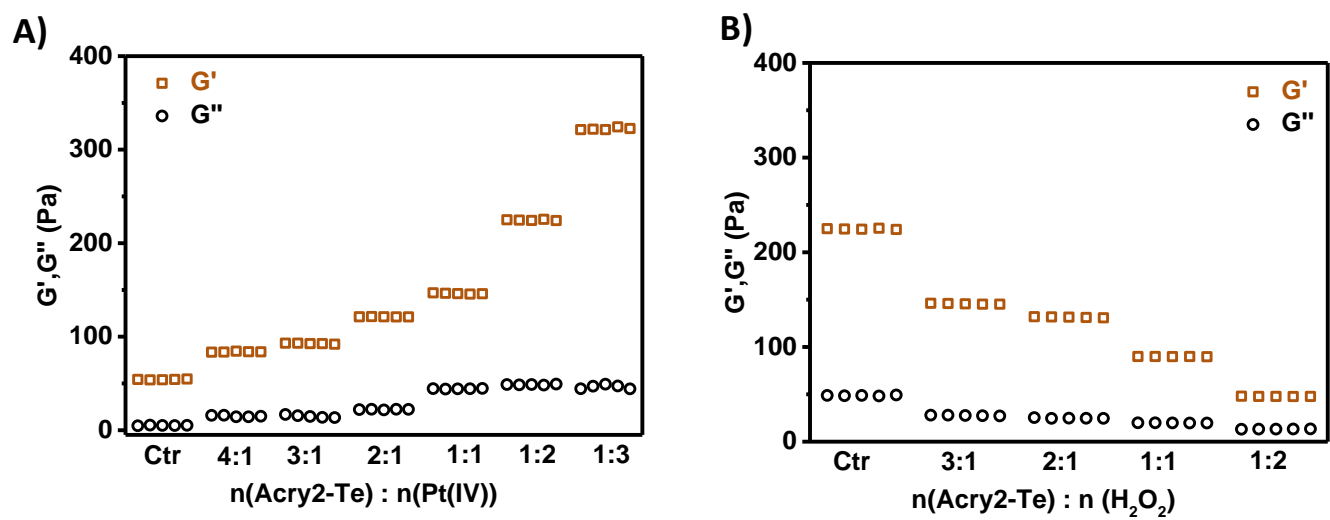

Figure S8. A) Rheology test results of hydrogel-20 made from HEMAA and Acry2-Te with different stoichiometric ratios of Acry2-Te and $\mathrm{PtCl}_{4}$. B) Rheology test results of hydrogels oxidized with $\mathrm{H}_{2} \mathrm{O}_{2}$ with different stoichiometric ratios of Acry2-Te to $\mathrm{H}_{2} \mathrm{O}_{2}$. Stoichiometric ratio of Acry2Te, HEMAA and $\mathrm{PtCl}_{4}$ was 1:20:2 in the hydrogel. 
Table S1. The binding free energies for $\left[(\mathrm{Pt})^{4+}(\mathrm{Te}) \mathrm{n}\right]$ and $\left[(\mathrm{Pt})^{4+}(\mathrm{TeO}) \mathrm{n}\right](\mathrm{n}=1-4)$ in vacuum and in water (polar solvent) calculated at the DFT/PBE level.

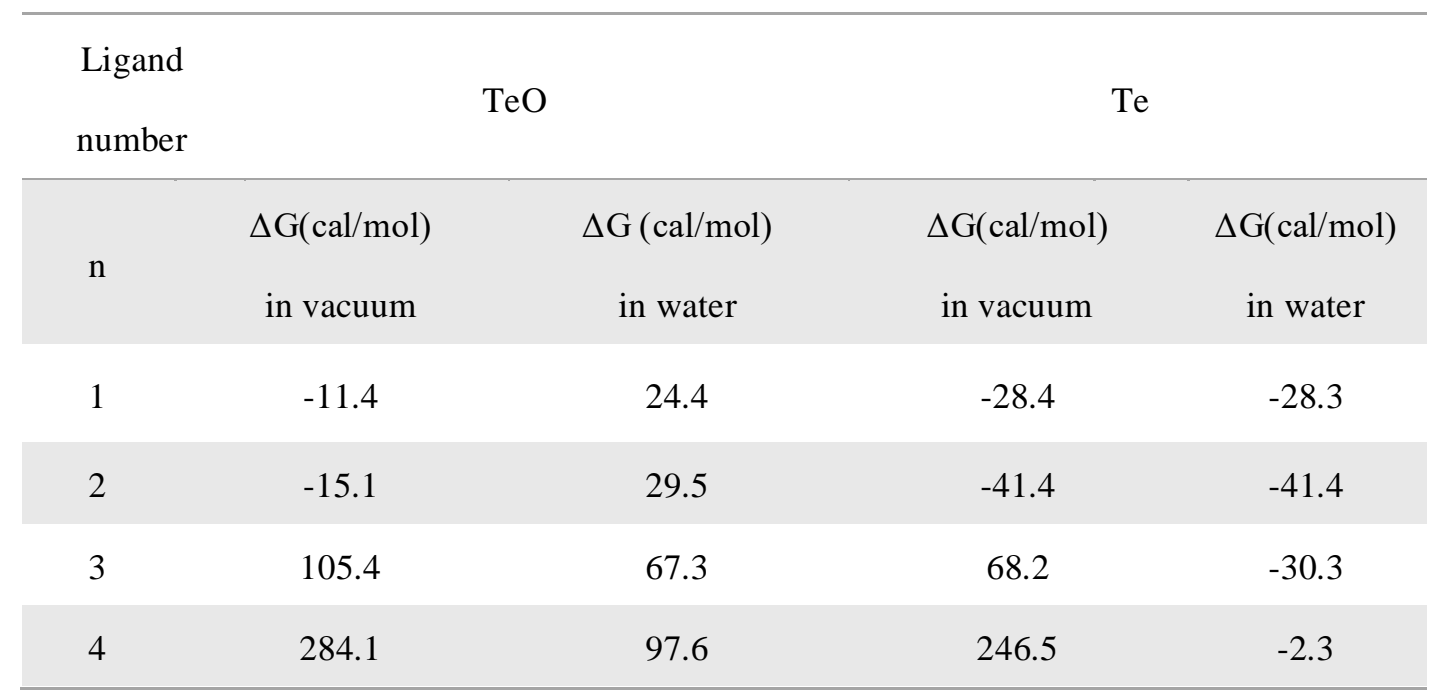

Table S2. Prescription for hydrogel with diverse stoichiometric ratios Acry2-Te monomer to HEMAA.

\begin{tabular}{ccccccccc}
\hline & $\mathrm{H}_{2} \mathrm{O}$ & Acry2-Te & HEMAA & APS & TEMED & $\mathrm{PtCl}_{4}$ & $\mathrm{H}_{2} \mathrm{O}_{2}$ & VC \\
Hydrogel & & $(0.56 \mathrm{M})$ & $40 \%$ & $10 \%$ & & $(0.1 \mathrm{M})$ & $(50 \mathrm{mM})$ & $(50 \mathrm{mM})$ \\
& $(\mu \mathrm{l})$ & $(\mu \mathrm{l})$ & $(\mu \mathrm{l})$ & $(\mu \mathrm{l})$ & $(\mu \mathrm{l})$ & $(\mu \mathrm{l})$ & $(\mu \mathrm{l})$ & $(\mu \mathrm{l})$ \\
\hline Gel-10 & 128.6 & 9.4 & 25 & 5 & 2 & 59.4 & 100 & 100 \\
\hline Gel-20 & 133.3 & 4.7 & 25 & 5 & 2 & 59.4 & 100 & 100 \\
Gel-40 & 135.7 & 2.4 & 25 & 5 & 2 & 59.4 & 100 & 100 \\
\hline
\end{tabular}




\section{References}

1. Andrae, D.; Häußermann, U.; Dolg, M.; Stoll, H.; Preuß, H. J. T. c. a., Energyadjustedab initio pseudopotentials for the second and third row transition elements. Theoretica Chimica Acta 1990, 77 (2), 123-141.

2. Bergner, A.; Dolg, M.; Küchle, W.; Stoll, H.; Preu, H., Ab initio energy-adjusted pseudopotentials for elements of groups 13-17. Mol. Phys. 1993, 80 (6), 1431-1441.

3. Wilson, A. K.; Woon, D. E.; Peterson, K. A.; Dunning, T. H., Gaussian basis sets for use in correlated molecular calculations. IX. The atoms gallium through krypton. $J$. Chem. Phys. 1999, 110 (16), 7667-7676.

4. Tomasi, J.; Mennucci, B.; Cammi, R., Quantum mechanical continuum solvation models. Chem. Rev. 2005, 105 (8), 2999-3093. 